\title{
The simulation of cold volumetric stamping by the method of transverse extrusion
}

\author{
Anatoly K. Belan ${ }^{1}$, Vladimir A. Nekit ${ }^{1, *}$, and Olga A. Belan ${ }^{1}$ \\ ${ }^{1}$ Nosov Magnitogorsk State Technical University, Lenin Street, 38, Magnitogorsk city, Chelyabinsk \\ Region, Russian Federation, 455000
}

\begin{abstract}
The article is devoted to the theoretical study and development of the production process of manufacturing rod products with larger heads by transverse extrusion. For carrying out researches the elastic-plastic finiteelement model based on the variation principle was chosen. This model, due to the development of a complex of boundary and initial conditions, has been adapted to the scheme of volume stamping of the fasteners and implemented in the form of a software package in the system DEFORM 3D.The paper presents the results of computer simulation of the technology of manufacturing the mortgage bolt
\end{abstract}

\section{Introduction}

With the development of mechanical engineering, automotive and construction, there is a growing need for sophisticated modern fasteners which allows you to create strong, highperformance, reliable and durable connections. These fasteners contain: flanged fasteners, self-drilling and self-tapping screws, their use greatly simplifies and speed up installation work [1].

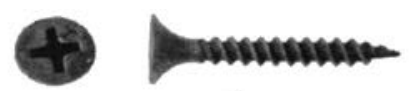

a)

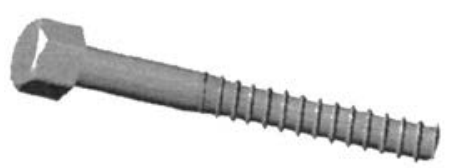

в)

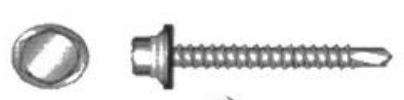

д)

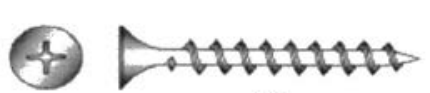

б)

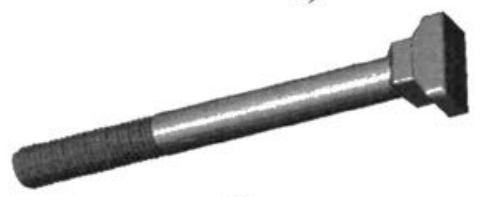

г)

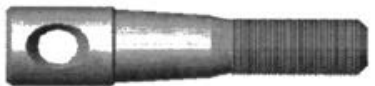

e)

Fig. 1. Items with long cone and an enlarged head.

To reduce terms of development and introduction of new types of fasteners the systems of the automated design and modelling allowing to model several options of the technology

*Corresponding author: vladimir@nekit.info 
and to choose the most optimum are applied [2-6].

For the transverse extrusion of such products special stamps are used [1]. Stamps for the transverse extrusion have a design that provides a rigid clamping of the work piece area. The head is forming in a closed volume by transverse extrusion.

The shape of the pre-head can be different (Fig. 2) and depends on where the head is formed: in the punch (a), the matrix (b) or partially in the punch and partly in the matrix (b). An important role plays the height of the cavity in the tool $h$, as this size determines the freely settled part of the work piece, not clamped at the beginning of the planting process.

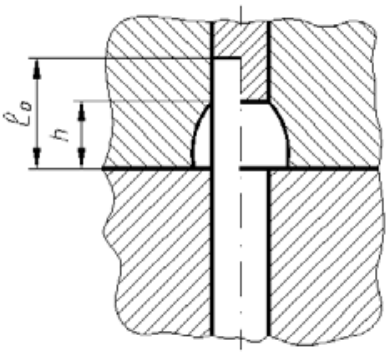

a

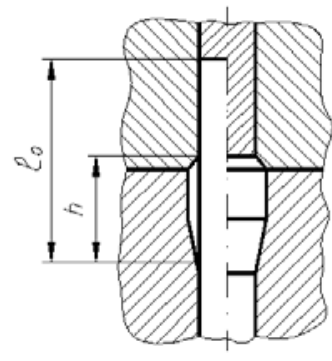

b

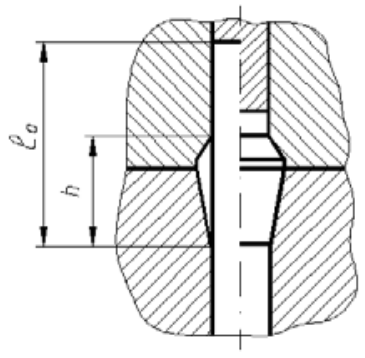

C

Fig. 2. Scheme of preliminary transverse extrusion of heads: $a$ - in the punch; b - in the matrix; c-in the punch and the matrix.

The problem of theoretical description of the transverse extrusion process can be solved with the help of models, capable of determining the stress-strain state of the entire volume of the deformed metal. The known methods of modelling often do not meet modern requirements, so they resort to numerical modelling of technological processes [7].

\section{Methodology}

Currently, the numerical finite element method [8-10] is widely used to solve the problems of mechanics of a solid deformable body. This method allows approaching solutions of technical problems in the conditions close to practical and connected with the features of production. Elastic - plastic finite-element model was chosen for the research [11-15].

This model, due to the development of a complex of boundary and initial conditions, has been adapted to the scheme of transverse extrusion of metal and implemented in the form of a software package in the system DEFORM 3D. As initial data in the mathematical modified model was generally accepted

-the size and shape of the tools (die and punch) and their location in space;

- dimensions and shape of the original blank;

- the speed of movement of the punch;

- the coefficient of friction included in the law of friction of the Amonton-Coulomb;

- mechanical properties of the deformable steel of a given grade in the form of true yield stress dependences on the degree and rate of deformation under isothermal conditions.

As a result of the problems solution a variety of characteristics, both distributed and integrated one, were found:

- the shape and location of the resulting product;

- the velocity fields, strain rate fields, displacement and strain fields, and intensities of tensor quantities;

- contact stresses and deformations, deformation force. 


\section{Results and discussions}

The numerical experiment reflects the process of transverse extrusion of the steel work piece. The metal fills the space of cylindrical shape in the body of the punch. Deformable material - steel 20, with the following contents of chemical elements ( $\%$ ): C- $0,17-0,24$; $\mathrm{Si}-0,17-0,37 ; \mathrm{Mn}-0,35-0,65 ; \mathrm{P} \leq 0,035 ; \mathrm{S} \leq 0,04$. The initial work piece - the cylinder with variable height and diameter of $5.25 \mathrm{~mm}$. The speed of movement of the punch 1 $\mathrm{mm} / \mathrm{s}$. Deformation scheme corresponds to Fig. 2a.

The results of the calculation of the deformation of blank with a diameter of $5.25 \mathrm{~mm}$ from steel 20 while transverse extrusion are shown in Fig. 3.
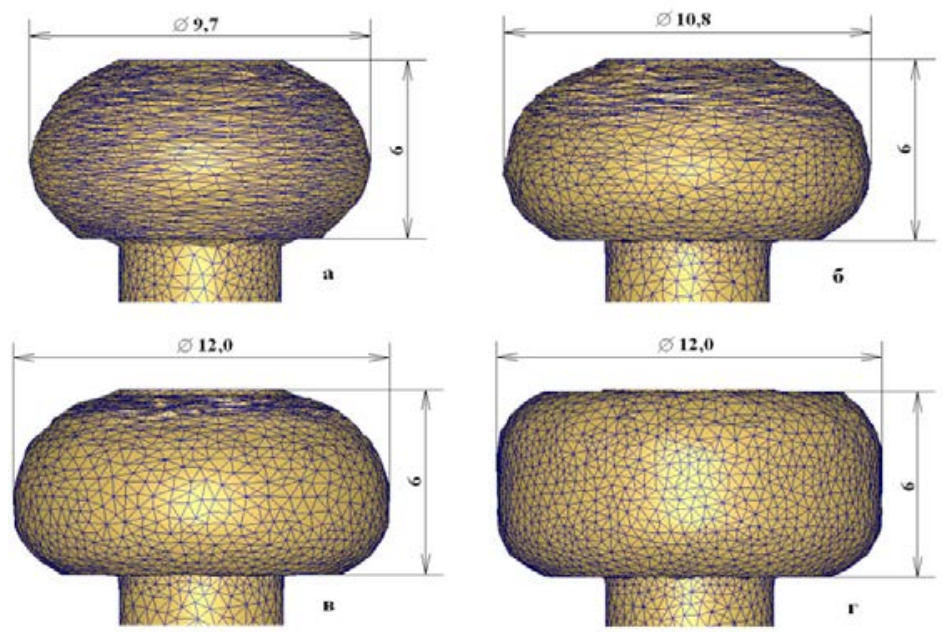

Fig. 3. The shape and dimensions of the heads obtained by transverse extrusion: $a-\varepsilon=71 \% ; \sigma-\varepsilon=$ $74 \%$ в $-\varepsilon=77 \% ; \Gamma-\varepsilon=81 \%$

The maximum value of the width increasing of the head is $6.76 \mathrm{~mm}$. The square of cross-section of the work piece $-21.64 \mathrm{~mm} 2$, the maximum square of cross-section of the head-113.04 $\mathrm{mm} 2$. The degree of deformation reaches $81 \%$.

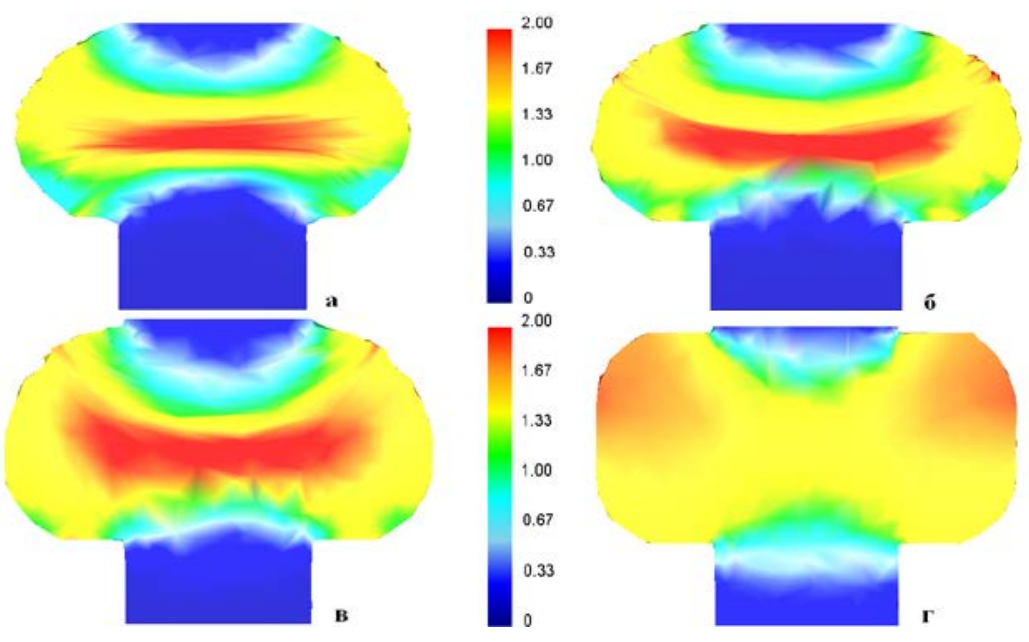

Fig. 4. Fields of strain intensity. $a-\varepsilon=71 \% ; \sigma-\varepsilon=74 \% ; \mathrm{B}-\varepsilon=77 \% ; \Gamma-\varepsilon=81 \%$ 
Fields of strain intensities, strain rates and stresses were calculated for all cases. Figure 4 shows the fields of strain intensities in the longitudinal section. Almost the entire volume of the bolt head has the highest stress intensity values, reaching $668 \mathrm{MPa}$ at the end of the first stage and $684 \mathrm{MPa}$ at the end of the second stage. The increase in this parameter is due to the hardening of the material during plastic deformation. During the transition to the rod values of the parameter of the stress intensity are smoothly reduced down to zero.

To verify the accuracy of the volumetric finite element model of the transverse extrusion process, experimental studies on deformation of the rod products were carried out. Tests were carried out on a press with application of the developed experimental installation allowing simulating process of transverse extrusion of work pieces. On the longitudinal section of the specimen of steel 20 before deformation was applied to a coordinate grid consisting of squares with side $1.05 \mathrm{~mm}$. Then the two halves were joined with help of glue of cold hardening, the work piece was compressed at the press with application of the developed experimental installation.

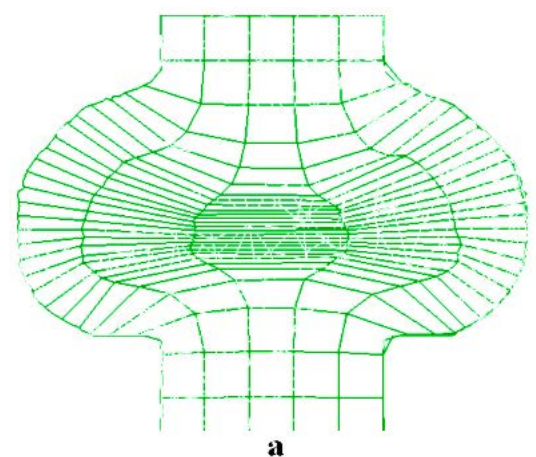

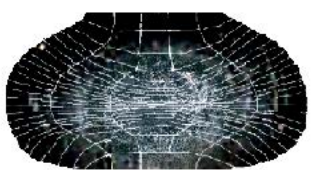

б

Fig. 5. Coordinate grid at the end of deformation in model (a) and on sample (b)

The results for twenty of the measurements showed, that the deviations of the calculated and measured values are in the range from 11 to $14 \%$.

Computer modelling has been applied in the development of technology of production of the bolt by the method of transverse extrusion. The fitting bolts (Fig. 6) used as a fastener for reinforced concrete supports.

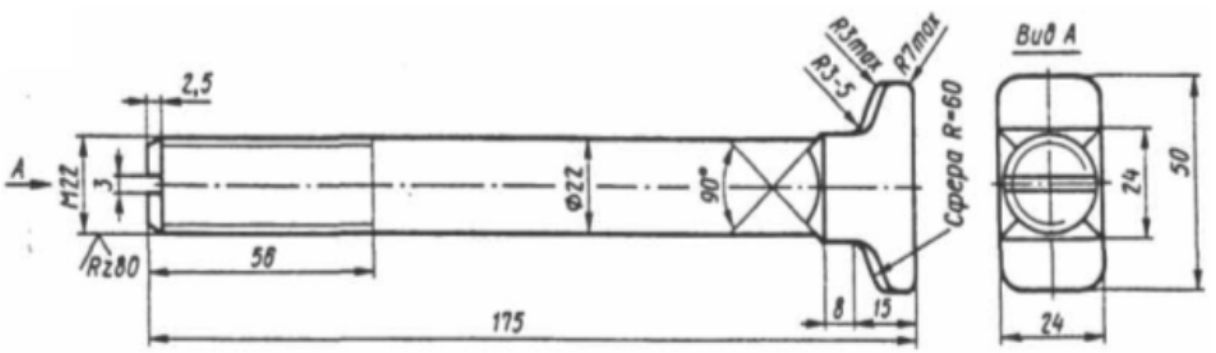

Fig. 6. The foundation bolt GOST 16017-79.

\section{Summary}

Description of the process of deformation of the metal in the working area of the die is the most difficult in the bulk stamping rod products with the larger heads. This is due to the complex shape of the head and the design features of the working tool. This process 
prevents the longitudinal bending of the work piece that distinguishes the process from free upsetting. The uniformity of the deformation is ensured by the double pinching of the work piece. The theoretical study and development of the production process of manufacturing rod products with larger heads by transverse extrusion have been conducted. The characteristics of the stress-strain state of the metal in the transverse extrusion process are determined. As a result of modelling the technological process of manufacturing of mortgage bolts is developed.

\section{References}

1. A. K. Belan, M. S. Malysheva, O. A. Belan, Cold stamping of heads of rod products by method of cross extrusion: Monograph., Magnitogorsk: GOU VPO "MSTU", 176 p., ( 2008)

2. A. K. Belan, M. S. Malysheva, O. A. Belan, Improvement of the process of lateral extrusion on the basis of mathematical modelling, Forging and stamping production, Processing of materials by pressure, v. 8, pp. $19-25,(2008)$

3. A. K. Belan, O. A. Belan, Mechanics and energy-power parameters of the transverse extrusion process, Forging and stamping production, Processing of materials by pressure, v. 2, pp. $21-24,(2011)$

4. A. K. Belan, M. E Motorigin, O. A. Belan, Applied mechanics stability in the processing of metals by pressure, Publishing house of Magnitogorsk state Technical University G. I. Nosova, 218 p.,( 2011)

5. A. K. Belan, O. A. Belan, The design of self-tapping screws and the technology of their production, Forging and stamping production, Processing of materials by pressure, v. 9, pp. $20-25,(2015)$

6. A. K. Belan, A. D. Kartunov, O. A. Belan, Development of design and production technology of self-tapping screws of increased strength in the conditions of $M M K$ METIZ. Modeling and development of metal forming processes, Magnitogorsk, State technical University G. I. Nosova, pp. 150-157, (2016)

7. Stephen. P., Twickler R., Foxen Y., Vegeroth K., Methods of numerical modelling for the development of technological processes, Ferrous metals, Moscow, Metallurgy, v. 4, pp. 37-43, (1992)

8. E. G. Diakonov, Numerical methods in continuum mechanics, Novosibirsk, USSR Academy of Sciences, , v. 7, № 5, pp. 14-78, (1976)

9. B. E. Pobedrya, Numerical methods in the theory of elasticity and plasticity, Moscow, MSU, P. 344/ (1981)

10. G. Y. Gong, Mathematical modelling of metal forming processes, Moscow, Metallurgy, 352 p., (1983)

11. A. M. Pesin, Modelling and development of asymmetric deformation to improve the efficiency of the sheet rolling, Dissertation for the degree of doctor of tech. sciences, Magnitogorsk, MSTU, (2003)

12. Kopp R, Domain P. M., Modelling and design of rolling processes with the finite element method, Ferrous metals, Moscow, Metallurgy, v.7, pp 62-68, (1990)

13. V. A. Nekit, E. M. Drigun, Hot stamping the bottoms of railway tanks in the conditions of the Magnitogorsk metallurgical combine, Iron and steel, , v. 11-12, pp. 68-70., (2000) 
14. V.A. Nekit, A. A. Pustovalov, A.V. Nekit, The method of determining the critical strain in uniaxial tension, Forging and stamping production, Processing of materials by pressure, 2003, No. 3, P. 29-30.

15. V. A. Nekit, Neutral section in the hearth of plastic deformation during rolling of strips, Modelling and development of processes of processing of metals by pressure, v. 18, pp. 137-139, (2012) 